Article

\title{
Effects of Specific Parameters on Simulations of Energy Use and Air Temperatures in Offices Equipped with Radiant Heating/Cooling Panels
}

\author{
Sabina Jordan ${ }^{1, *}$, Jože Hafner ${ }^{1}$, Martina Zbašnik-Senegačnik ${ }^{2}$ and Andraž Legat ${ }^{1}$ \\ 1 Slovenian National Building and Civil Engineering Institute, Dimičeva ulica 12, 1000 Ljubljana, Slovenia; \\ joze.hafner@zag.si (J.H.); andraz.legat@zag.si (A.L.) \\ 2 Faculty of Architecture, University of Ljubljana, Zoisova cesta 12, 1000 Ljubljana, Slovenia; \\ martina.zbasnik@fa.uni-lj.si \\ * Correspondence: sabina.jordan@zag.si
}

Received: 20 August 2019; Accepted: 26 October 2019; Published: 30 October 2019

Featured Application: This work can contribute to more accurate modeling of dynamic simulations, used for important strategic decisions about the performance of buildings equipped with new technologies or for simulating buildings based on innovative building concepts.

\begin{abstract}
When creating a simulation model to assess the performance of buildings, there is usually a lack of feedback information. Only in the case of measurements of a real building is a direct comparison of the measured values and simulated results possible. Parameter data related to users' behavior or other events can also be obtained. Their evaluated frequency, magnitude and duration, along with boundary conditions, are crucial for the results. It is clear that none of them can be predicted very accurately. Most of them, however, are needed for computer modeling. In this paper we analyzed the well-defined TRNSYS simulation model of offices equipped with radiant ceiling panels for heating and cooling. The model was based on real case offices and was validated based on measurements for 1 year. The analysis included simulations in order to define what effect the parameters related mainly to users have on the energy use and the indoor air temperatures. The study confirmed that specific human activities influence the annual energy use to a relatively small degree and that their effects often counteract. It also confirmed the even more important fact that although small, these activities can influence the thermal comfort of users. It is believed that despite the fact that this research was based on an analysis of offices equipped with radiant ceiling panels, most of the results could be applied generally.
\end{abstract}

Keywords: measurements; modeling; simulation; validation; analysis; energy use; temperature

\section{Introduction}

The energy efficiency of buildings is the foremost characteristic of a sustainable built environment, and one that can also affect the thermal comfort of users. In order to improve buildings in this respect, various analyses can be carried out. The importance of the analyses is particularly evident in the introduction of new technologies that need to be evaluated for their general performance and energy efficiency in different integration concepts. Such technical assessments can be achieved by performing different kinds of tests and measurements. The latter are particularly successful when combined with real-case demonstrations [1-3]. On the other hand, modeling by means of various mathematical tools is also a powerful technique for evaluating the impact of new technologies on thermal comfort and energy use $[4,5]$. However, the most effective method is certainly to combine the two approaches in 
a so-called empirical validation, since this enables the calibration of the model and the validation procedure [6-9], and consequently enables improvements in technology and design.

Building analyses are often implemented through dynamic simulation programs that model parts or all of a building. However, creating a reliable simulation model equipped with relevant data is essential for the results. Additionally, occupants' activities and other events can influence the indoor temperature, and thus can have an important influence on the operation of heating and cooling systems and consequently the energy use. Actually, one of the most relevant gaps that was identified by researchers was the difference between the real energy performance in a building and the performance predicted at the design stage, which is mainly due to occupant behavior [10]. But, what levels of frequency, intensity and duration for such events are crucial for the system, and should they be included in the model? While it is clear that none of these events can be predicted with great accuracy, some of them can be among the causes of the huge discrepancy between the predicted and the real energy use in buildings.

One of the powerful tools for performing dynamic simulations is TRNSYS [11], which is a commonly used software for analyzing the energy efficiency and thermal comfort of large models, e.g., buildings or building elements $[4,6]$ under unsteady-state conditions. The program can also be used for dynamic simulations of buildings equipped with radiant systems [3,12]. In a few older studies involving TRNSYS computer simulations of a typical office floor equipped with a radiant cooling system, it has already been established that occupant behavior can have an important influence on the cooling needs and the thermal comfort [3]. Similar conclusions have been made in investigations of the possible influence of occupant behavior on a building's performance and the thermal comfort in conventionally heated buildings: compared to the design strategy used in the model, the measured energy demand can be twice as high and the thermal comfort much lower [13]. By means of simulations on the model, which was calibrated using measured in-situ data, Tian [14] demonstrated that certain limitations of the measured data can contribute significantly to the observed discrepancies between the measured and simulated results. In a case study, research on the German net-zero-energy-building Ascione [15] demonstrated a performance gap between the expected and the measured electrical energy performance, especially for heating, lighting, ventilation, auxiliaries and equipment. According to his research, the reasons for that are related to the pattern of use of the buildings and to the occupants' behaviors. In fact, a much higher energy demand, 2.7 times the expected request, has been found for heating (including DHW production, which has a very low impact), while those for ventilation, lighting and equipment are much lower, about $-36 \%,-33 \%$ and $-14 \%$. According to D'Oca [16], energy-usage simulations in models of dwellings in which the occupants' window opening and heating set-point adjustments are set by probabilistic functions (inferred from field measurements), were up to $61 \%$ higher than when the control system was simulated in a deterministic way using fixed schedules.

In general, Ryan [17] claims that although building energy models have improved over the years, there have been no major improvements in the methods used to model occupants' behavior and that these methods require detailed monitoring of the building's occupants. According to Carlander [18], however, two more things are needed, i.e., time diaries and interviews, which together with logged measurements can be great tools to detect behavior that affects energy use in buildings. They can also be used to create detailed schedules and behavioral models for building energy-simulation models so that they are better at predicting actual energy use [18]. As regards the influence of building-occupant behavior on energy efficiency, Paone [19] stated that introducing energy-conservation measures without taking into account user satisfaction can often be counter-productive, because users are likely to try to adapt their environment to have comfortable conditions. These kinds of actions can include some key changes, such as opening windows, shading maneuvers and adjusting the air temperature, which need to be anticipated. In this sense, a number of studies have recently been conducted dealing with occupants' behavior and factors influencing occupants' behavior and models [20-23]. In his comprehensive study, Hong [20] highlighted the ten most important issues regarding energy-related occupant-behavior research and applications in buildings. According to the research of Fabi [22], more 
accurate, reliable and realistic occupant-behavior models still need to be developed. One of them was developed by Hong [23], i.e., a framework of occupant behavior with the aim to allow the incorporation of more accurate behavioral models into building-simulation tools to provide comparable metrics and results on: (1) the behavioral factors that impact building energy performance; (2) the potential energy savings from improved occupant behavior in buildings; and (3) the design of robust building operation scenarios, technologies, systems and retrofit strategies. IEA EBC Annex 66 is dealing specifically with the definition and simulation of building-occupant behavior. According to Annex experts, the occupant-behavior models developed by different researchers are often inconsistent, with a lack of consensus in common language, good experimental design and modeling methodologies [24]. In his work, Yan [25] highlighted the key research issues, methods and outcomes contained in Annex 66. One important finding was that the methods for collecting data, which are fundamental to the modeling of occupant behavior, are evolving rapidly and simultaneously with sensors and ICT.

Studies of the impact of real occupant behavior in buildings at the detailed level are scarce. In addition, as Tam [10] found in his review, further analyses of the interactions between technological improvement and behavioral change are needed to influence the energy effect of occupant behavior, to better understand occupant behavior driven by feedback and anticipate actual building performance. Nevertheless, since occupant behavior is unpredictable, a variety of techniques are nowadays used in behavior-related modeling; for instance, agent-based modeling (ABM) and multi-agent systems (MASs), which have a clear record of success, and other predictive techniques, such as fuzzy modeling, neural networks and Markov chains. However, a review by Rafsanjani [26] indicated that further research is needed on how these new techniques can be integrated into current energy-simulation software or developed as new software.

To calculate the impact of different parameters on the system or to define the sensitivity of the system, the variations in the building or user-related parameters are included in the building simulation models [27-29]. In some cases, even the meteorological parameters are involved [30]. To analyze such systems a very complex sensitivity analyses can be used, usually in combination with uncertainty techniques. The sensitivity analyses can also be applied to understand the relationships between the input and output variables in a model. In his work on a nearly-zero-energy building (NZEB), Sun [28] systematically investigated the impact of three sets of macro parameters using differential sensitivity analyses (DSA), and then linked the results to the costs. He found that all the building system sizes and the overall initial investment costs in an NZEB are most sensitive to the indoor temperature set-point. Similarly, a very extensive analysis was performed by Pacheco-Torresa [31], who, using sensitivity analyses on selected buildings, investigated whether the same set of parameters was relevant to the user. In the case of many input variables, it is advisable to first perform sensitivity analyses and then uncertainty analyses. Namely, sensitivity analyses can significantly reduce the computational costs by selecting key factors that affect the energy performance of a building [32]. In highly complex systems, it is often necessary to perform comprehensive sensitivity analyses, which may also be multi-stage sensitivity analyses with design optimization [27]. In our case, the number of variables was limited to the measured data related to specific events in real offices, such as window opening, use of internal blinds and adjustments of temperature setting. This somehow simplified the parameter-impact study, but on the other hand, these measured data can represent valuable information about selected details that were investigated in the study.

The purpose of this paper is to analyze the effect of various parameters on the simulation results from a TRNSYS model that was used to replicate real offices, as far as possible. The parameters were mainly associated with the users' presence and behavior when using the premises. They were obtained from measurements made on offices that were pilot demonstrators in the EU project COST EFFECTIVE (Resource- and Cost-Effective Integration of Renewables in Existing High-Rise Buildings, 7FP, 2008-2012) [33]. The parameters were used in a TRNSYS model that was based on the actual technical performance of the existing offices equipped with radiant heating/cooling ceiling systems. The TRNSYS model was validated by a comparison with the results of the measurements $[1,34,35]$. Our first 
objective was to compare how the particular parameters that were obtained from the measurements influence the final values of the simulated energy use and to what extent they affect the average indoor air temperatures of the validated numerical model. The second goal was to establish how certain parameters related to the use of the building can be generalized and how much they affect the matching with the results of the validated numerical model by means of a comparative analysis.

\section{Materials and Methods}

The numerical TRNSYS model was based on a real case geometry of four interconnected single-floor offices, partitioned by interior walls, and the data collected from monitoring these offices. The offices and the model itself have an area of $108 \mathrm{~m}^{2}$, with the orientation of the facade being $15^{\circ} \mathrm{SW}$, and represent a small part of the fifth floor of an office building in Ljubljana, Slovenia $\left(46^{\circ} 40^{\prime} \mathrm{N}, 14^{\circ} 31^{\prime} \mathrm{E}\right)$. (Figure 1a) The location has a typical mixed climate, with some continental and Mediterranean characteristics, i.e., warm summers and moderately cold winters.

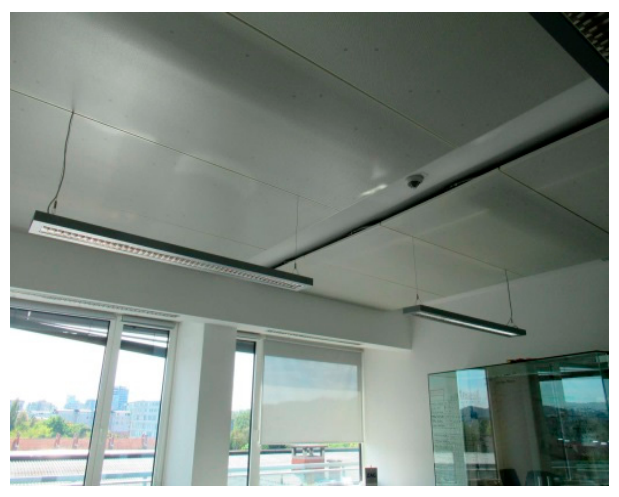

(a)

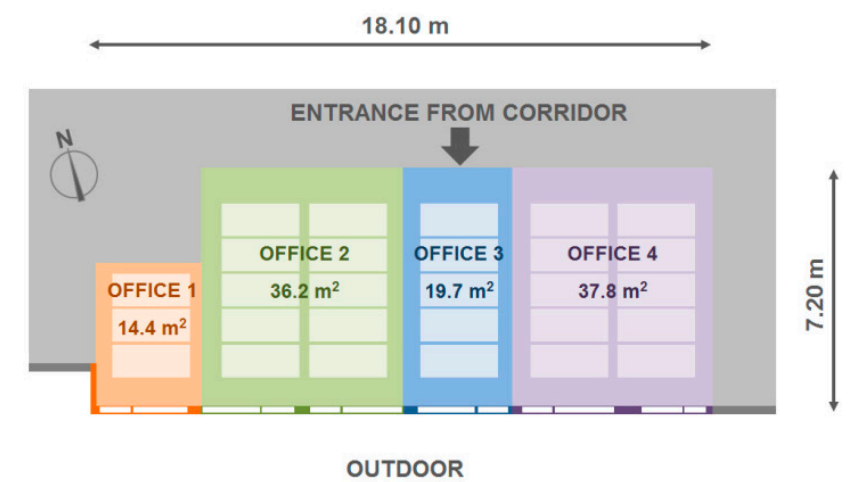

(b)

Figure 1. (a) Office 2 of premises which were the basis for modeling; (b) schematic floor plan of the offices with the radiation ceiling panels indicated by the brighter rectangles.

These four offices were the subject of an extensive retrofit of the building envelope, the installation of water-filled ceiling heating/cooling panels, the installation of mechanical ventilation (with recuperation) and the renovation of the electrical system. The ceiling panels were designed as large metal sheets over the copper piping, covering roughly $60 \%$ of each office ceiling slab (Figure $1 \mathrm{~b}$ ) with no thermal insulation layer. In the product specification the cooling power was $80-90 \mathrm{~W} / \mathrm{m}^{2}$ per $10 \mathrm{~K}$, whereas the heating power was $60-70 \mathrm{~W} / \mathrm{m}^{2}$ per $10 \mathrm{~K}$ of the temperature difference. Since the temperature difference in the offices can reach up to $7 \mathrm{~K}$ in the cooling mode, and up to $14 \mathrm{~K}$ in the heating mode, the power of the panels in the cooling mode can be as high as $63 \mathrm{~W} / \mathrm{m}^{2}$, while in the heating mode it can reach $91 \mathrm{~W} / \mathrm{m}^{2}$.

The HVAC system was installed as a separate and autonomous energy system with its own solar power supply, and as such was equipped with sensors, metering devices and other supporting monitoring equipment. The ceiling heating/cooling panels were equipped with calorimeters to measure the amount of energy delivered to each office and with inlet/outlet temperature sensors. Also, the inlets and outlets of the mechanical ventilation system for transport of the tempered air in each office were equipped with electronic volume regulators and temperature sensors.

All the office systems were designed to be managed by the newly installed building management system (BMS). The purpose of the BMS is to collect the measured values and give commands to each part of the system according to the measured values and logic (schedules) that are built in.

As in the real offices, the geometry of the TRNSYS model involved four main zones and an unconditioned attic above them as a surplus fifth model zone. Each of the four office zones in the model was subdivided into five equal horizontal layers, each containing one thermal node. A total 
of 20 air thermal nodes were implemented. The system of nodes in the simulations was harmonized with the installation of the measurement locations of the air temperature in each of four offices, which consisted of five vertically installed temperature sensors arranged over the height of the room. This enabled a direct comparison between the measured and simulated air temperatures with the similarly distributed thermal nodes in the model without any ambition to run the heating/cooling system or evaluate the user's thermal comfort.

The model was completed using a TRNSYS Type 56 block [11] with an identical structure of the building elements and indoor furnishings to the real offices. The main construction material of the building elements was concrete, with the exception of the internal walls, which were made of a lightweight gypsum sandwich or brick. The facade and the ceiling of the unheated attic were thermally insulated $\left(\mathrm{U}_{\text {facade }}=0.28 \mathrm{~W} /\left(\mathrm{m}^{2} \mathrm{~K}\right), \mathrm{U}_{\text {ceiling }}=0.18 \mathrm{~W} /\left(\mathrm{m}^{2} \mathrm{~K}\right)\right)$. High-performance aluminium window frames $\left(\mathrm{U}_{\text {frame }}=1.60 \mathrm{~W} /\left(\mathrm{m}^{2} \mathrm{~K}\right)\right.$ with triple glazing, argon-gas filling and low-e coatings $\left(\mathrm{U}_{\text {glazing }}=0.70 \mathrm{~W} /\left(\mathrm{m}^{2} \mathrm{~K}\right), \mathrm{g}=0.3\right)$ were used for the windows. With a $15^{\circ} \mathrm{SW}$ exposure, the windows in the model correspond to the exposure of windows in real offices. The modeled windows also correspond to the actual window-to-wall ratio, which was calculated to be $46 \%$, and to the glazing-to-wall ratio of $36 \%$. The thermal capacitance of the interior furnishings and the radiant ceiling panels was estimated and included in the model as well. To define the air permeability of the building envelope, on-site measurements according to a standardized measurement procedure [36] were provided.

The model was supplemented by an existing routine defined in TRNSYS, i.e., the layer-type chilled ceiling [11], used for the simulation of a radiant ceiling system with a radiant energy-transfer coefficient of $8.3 \mathrm{~W} /\left(\mathrm{m}^{2} \mathrm{~K}\right)$ and a nominal water flow of $30 \mathrm{~kg} /\left(\mathrm{m}^{2} \mathrm{~h}\right)$. The regulation of the layer-type chilled ceiling was implemented in the same way as in the real offices, i.e., via virtual room temperature regulators. The air temperatures were set to $22^{\circ} \mathrm{C}$ in the heating mode (with night-time reductions of $1 \mathrm{~K}$ and weekend reductions of $2 \mathrm{~K}$ ) and $24^{\circ} \mathrm{C}$ in the cooling mode (with adjustments of $\pm 2 \mathrm{~K}$ ). The mechanical ventilation system in the model was simulated in the same way as the inlets and outlets of air in the real offices and with the air inlet quantity and the temperature $23-24{ }^{\circ} \mathrm{C}$ for both the heating and cooling modes. In reality, a surface condensation in the cooling period could cause serious problems with the cooled panels. Therefore, to avoid the risk of surface condensation, the amount of moisture in the ventilated air was reduced. Also, if the sensors detected a certain increase in the air-humidity rate, the system increased the water temperature in the ceiling panels. Additionally, if a window in an office was opened, the system stopped operating. When modeling, the same temperatures for the cooling media were applied as were measured in the offices.

The external conditions as well as the boundary conditions of the indoor environment were taken into account for the simulations. External conditions were applied to the facades and the roof of the fifth zone, while internal boundary conditions were applied to all the internal building elements, except the offices' ceilings. With the introduction of the attic zone the influences of solar radiation on the roof, the ambient temperature, the internal gains of the mechanical appliances and the air-change rate of attic were incorporated into the model. The indoor attic zone parameters (internal gains, air-change rate) were first based on estimations. However, periodic measurements of the attic's air temperature allowed a comparison of the measured and simulated temperatures and consequently fine-tuning of the parameters used in the model. The data for the external conditions that were used in the model, i.e., the one-year ambient temperatures and the solar irradiation for Ljubljana, were provided by the Slovenian Environment Agency [37]. Solar gains through the windows of the model were calculated automatically by the software. The regulation parameters of the solar gains by means of venetian blinds were estimated based on monitoring of the use of the venetian blinds in all four offices. These estimated values were used in the model and then gradually corrected and fine-tuned via several repeated simulations based on a comparison of the measured and simulated indoor-air temperatures. The estimated shading coefficient varied between 0.40 and 0.80 , with the minimum factor being typically applied in January and December. The shading coefficient of the internal roller blinds, estimated to be 0.30 and ultimately serving to reduce the glare in the real offices, was employed 
in the model as well. The indoor boundary conditions of the model were defined on the basis of measurements made in adjacent rooms and corridors.

Based on the assessment of the internal gains of real offices, the following three types of heat gains were taken into account: office users (estimation: light work), devices and artificial lighting. Internal gains from users amounted to $75 \mathrm{~W}$ per person, with only the sensible heat being taken into account [38]. The calculation was based on the average daily values on working and non-working days, and summarized by total values, separately for the heating and cooling periods. The average for all the offices in the heating season amounted to $22.4 \mathrm{kWh} /\left(\mathrm{m}^{2}\right)$, while in the cooling season the average was $14.3 \mathrm{kWh} /\left(\mathrm{m}^{2}\right)$.

A schematic of the TRNSYS numerical model for simulating the energy use and indoor air temperature of the offices is presented in Figure 2. This figure shows how the measured data were integrated into the model and that they represented a key input for the simulations. The measured updated data of each parameter represented the values for the new input of the next loop. Similarly, based on the analysis of the monitoring data, the process of scheduling adjustments was gradually integrated.

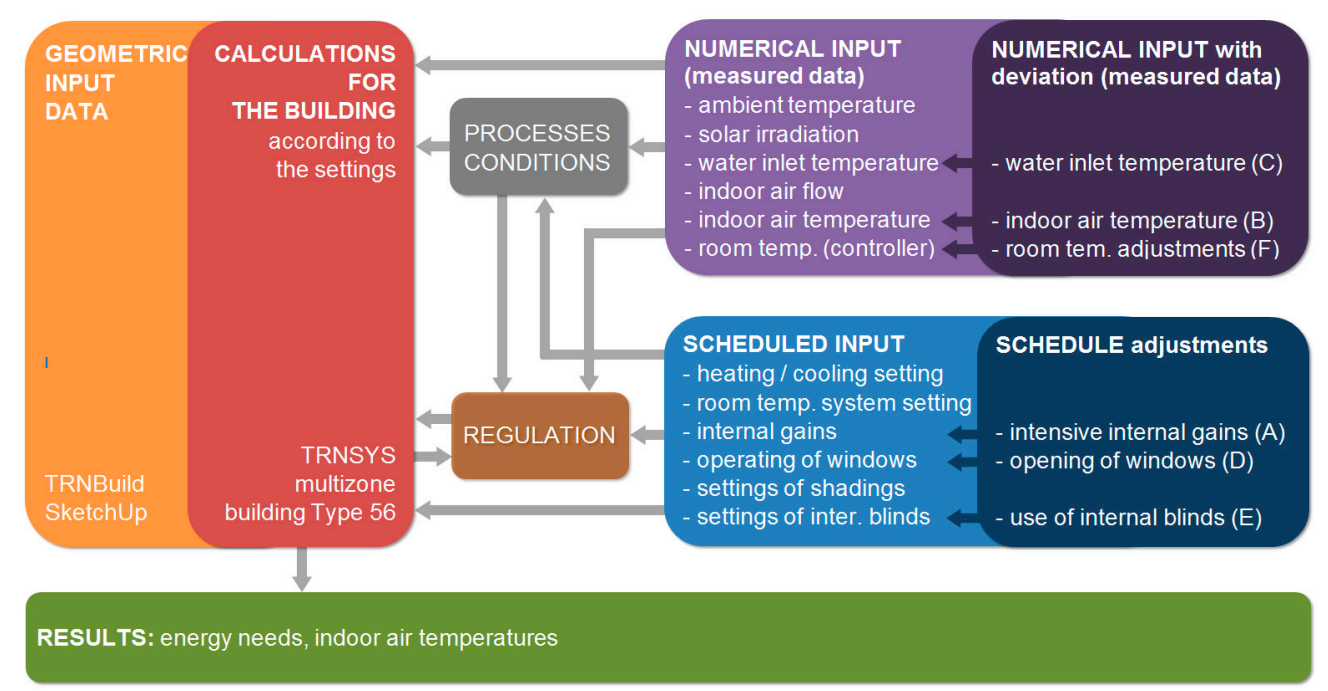

Figure 2. Schematic structure of the TRNSYS numerical model for the simulations of the offices with a basic structure of inputs, with numerical inputs having the deviation according to the measured data (cases C, B and F, according to Table 1), and scheduled inputs with adjustments (cases A, D and E, according to Table 1).

A more detailed description of all the building elements, the mechanical equipment and the management data that were used in the model can be found in $[1,34,35,39]$.

The TRNSYS model of the offices was validated based on a comparison with the measurement results obtained from the above-mentioned real-case offices. The validation was made for each month throughout the whole year and consisted of regular assessments of the measured and simulated indoor air temperatures and energy use. Percentage values of the root-mean-square error (RMSE) and the mean-bias error (MBE) for the simulated energy from the office panels and for the air temperatures were calculated [35] according to the established protocols [40,41].

The result of the analyses showed that the simulated annual heating energy released by the ceiling panels was $2.0 \%$ higher than the measured energy use, whereas the simulated annual cooling energy released by the ceiling panels was $0.2 \%$ lower than the measured energy. On an annual basis, the simulated energy use was only $0.8 \%$ higher than the measured energy that was released into the offices through the radiant ceiling panels. Moreover, the simulated average indoor air temperatures in the offices matched the measured indoor air temperatures very well. The average RMSE of the simulated 
temperature values for all four pilot offices was $\pm 0.45 \mathrm{~K}$ in the heating season and $\pm 0.58 \mathrm{~K}$ in the cooling season.

\section{Results}

\subsection{Comparison Basis for Energy Use and Indoor Air Temperature}

The use of energy in offices generally depends on several factors, for example, the type of building, its energy efficiency, the energy systems, the climatic and local conditions, as well as the type of use, i.e., the activities of the users themselves, which are changing over the course of the day, week and year. In our case, the energy needs of the ceiling radiation system were monitored for individual premises by the month and over the whole year. Due to the different parameters and the influences of a particular season, the use of energy was processed on a seasonal level, i.e., separately for the heating and cooling seasons, and finally on an annual level. The energy use was presented cumulatively for all the offices.

The second indicator that we followed was the indoor air temperature, which is usually the target category in the indoor built environment. In addition to the surface temperatures of the rooms, the indoor air temperature is one of the most important parameters for the user's thermal comfort. In general, the goal is to maintain the indoor air temperature at a certain level by providing energy to the buildings. When effectively controlling the heating and cooling systems, the fluctuations of the indoor air temperatures are minimized to acceptable average air temperatures during the daily and seasonal external temperature changes. In our example, for offices in Ljubljana, the target value for the average indoor air temperature in the heating season was $22^{\circ} \mathrm{C}$, while in the cooling season it was $24^{\circ} \mathrm{C}$. In the modeled offices, these values were calculated from the simulation results and compared with the analyzed monitored data from the real offices.

\subsection{Effect of Six Specific Parameters Included in the Validated Model}

When modeling the thermal performance of a building, there is usually a lack of specific detailed information. The situation in our case was the opposite, since we obtained a lot of data from the long-term monitoring that we carried out in the offices. These data were analyzed and the known values were used in numerical simulations to optimize and validate the numerical model, which was complex since it included all the important elements and parameters.

The validated numerical model was then used as a basis for the analysis of the effect of six parameters on the energy use and on the indoor air temperatures in the offices if these parameters are excluded from the simulation. The parameters were mainly related to the user's behavior in the offices, with only a few of them being attributed to the consequences of technical issues. These six parameters were as follows: intensive internal gains, additional extraction of energy with exhausted air from the mechanical ventilation system due to temperature differences, insufficient energy supply for cooling due to stopping the operation of the cooling system in the summer, window opening by the occupants, use of internal roller blinds by the occupants and temperature adjustments using room controllers by the occupants. The effect of their exclusion from the model was observed both seasonally and annually. The simulations were made one by one so that the specific parameters were individually excluded from the validated model (Table 1, rows A to F). Table 1 also shows the results for the validated model with all the specific parameters included (first row) and also for the validated model from which all six parameters are excluded (row G).

The results of the analyses, the effect of each individual specific parameter excluded from model and the combined effect of all six of them, are presented in Figure 3 in comparison with the results from the simulation on the validated model. 
Table 1. Specific parameters in the analysis of the validated model and their influence on the simulation results for energy use at annual level.

\begin{tabular}{|c|c|c|c|c|c|c|c|}
\hline & & \multicolumn{3}{|c|}{ Description of Specific Data } & \multicolumn{3}{|c|}{$\begin{array}{l}\text { Energy } \\
(\mathrm{kWh} / \mathrm{a})\end{array}$} \\
\hline & & Frequency & Duration & Location & $\begin{array}{l}\text { Heating } \\
\text { Mode }\end{array}$ & $\begin{array}{l}\text { Cooling } \\
\text { Mode }\end{array}$ & Total \\
\hline & $\begin{array}{c}\text { Validated model } \\
\text { (all six specific data included) }\end{array}$ & - & - & - & 1452.3 & 1806.3 & 3259.6 \\
\hline A & $\begin{array}{l}\text { Validated model } \\
\text { without intensive internal gains }\end{array}$ & Once & 6 days (Mar) & Office 4 & 1486.1 & 1806.0 & 3292.1 \\
\hline B & $\begin{array}{l}\text { Validated model } \\
\text { without extraction of energy with } \\
\text { exhausted air }\end{array}$ & Continuously & Whole year & All offices & 1438.2 & 1933.2 & 3371.5 \\
\hline $\mathrm{C}$ & $\begin{array}{l}\text { Validated model } \\
\text { without insufficient energy supply for } \\
\text { cooling }\end{array}$ & Once & 5 days (Aug) & All offices & 1450.1 & 1853.5 & 3303.7 \\
\hline $\mathrm{D}$ & $\begin{array}{c}\text { Validated model } \\
\text { without window opening by users }\end{array}$ & Regularly & Whole year & All offices & 1423.0 & 1938.4 & 3361.4 \\
\hline E & $\begin{array}{c}\text { Validated model } \\
\text { without use of internal roller blinds }\end{array}$ & Continuously & Whole year & All offices & 1414.0 & 1859.4 & 3273.4 \\
\hline $\mathrm{F}$ & $\begin{array}{l}\text { Validated model } \\
\text { without temperature adjustments at } \\
\text { regulators }\end{array}$ & Continuously & Whole year & All offices & 1262.5 & 1423.0 & 2685.5 \\
\hline G & $\begin{array}{c}\text { Validated model } \\
\text { without all six specific data }\end{array}$ & - & - & - & 1221.8 & 1769.4 & 2991.2 \\
\hline
\end{tabular}

The first analyzed specific parameter was the unexpected and large internal gains in Office 4, which occurred in March of the monitored year. The analysis of the monitored data revealed that an extra expert was working in this office for 6 days; he was using a supplementary computer and a 3D scanner, which caused a noticeable amount of heat gain in the office. These additional internal gains, which were large but short term, were included in the model when optimizing it for the validation. However, when excluded from the model, they have a relatively moderate seasonal effect on the energy use, i.e., $2.3 \%$ in the heating season. If they had been observed with regards to the annual energy level, their influence would have been relatively small: according to the results of the simulations, $1.0 \%$ more energy is needed for heating per year if these additional internal gains are excluded from the model. Also, the calculated average indoor air temperature based on the simulations showed practically the same values for the heating season as with the validated model (Figure 3).

A very similar situation also applies to the extraction of energy from the exhausted air produced by the mechanical ventilation due to unpredicted air-temperature differences in the offices. This parameter was included in the optimized model based on the analysis of simple measurements of the gradient of air temperatures in all the offices. The energy effect of the extraction of this extra heat produced by the exhausted air flowing through the air outlets of the mechanical ventilation system in the cooling season was significant. The simulations showed that if this parameter was excluded from the model, $7.0 \%$ more energy was used for the cooling, which confirms that the air temperatures in the upper air layers of the rooms, close to windows, can be considerably higher than in the other locations in an office. During the heating season, however, the above-mentioned air temperature differences were relatively small. Consequently, the energy influence was only $1.0 \%$ and was counteracting. Nevertheless, the simulations on the model with no extraction of heat with exhausted air through the mechanical ventilation system's air outlets due to unpredicted air-temperature differences resulted in a moderate $3.5 \%$ higher total energy use. The simulations also revealed that this continuous operation affects the average air temperatures to a negligible extent (Figure 3).

The monitoring revealed some additional details. A thorough overview of the temperature curves and the system's performance showed that there was a deviation in the cooling system in the summer. During the hottest days in August, there was a slight deficit of cooling energy in the mechanical system, which caused the entire cooling system to operate with reduced power for 5 days. The use of energy 
for cooling therefore decreased by $2.6 \%$. Nevertheless, this was the effect detected at the seasonal level. In annual terms, the malfunctioning due to insufficient energy supply for cooling caused an insignificantly low result of $1.4 \%$. Regarding the average indoor air temperature, the simulations showed an influence only during the cooling season, which, however, was also very small for this case: the average indoor air temperature deviated by less than a tenth of a degree from the validated one (Figure 3).

The next feature of our analysis of the measured results was the opening and closing of the windows by occupants, especially during the heating and cooling seasons. Therefore, the validated model also included this data. However, when excluded from the model (i.e., all the windows are closed), the simulation results showed that $2.0 \%$ less energy was needed for the heating. It should be noted that the offices were mechanically ventilated and, in this respect, there was no need to open the windows for fresh air. A random and infrequent opening of the windows during the heating season was a result of the psychological needs of the occupants. This also resulted in a small influence of the window opening on the energy use in the offices during the heating period. In the cooling season, in contrast, the simulation results without window opening revealed a 7.3\% increase in energy use. This clearly showed that occupants opened the windows very thoughtfully: mainly when the outdoor air temperatures were lower than the indoor air temperatures. Nevertheless, both effects resulted in a moderate $3.2 \%$ higher annual energy use. If we observe the calculated indoor average air temperatures, the simulations showed very similar results: by opening windows, the users only had a slight influence on the air temperature during the cooling season (they were able to decrease it slightly), while in the heating season the influence of the window opening was much smaller (Figure 3).

The effect of the use of internal roller blinds was investigated. Occupants' activities, such as their daily use of roller blinds for protection against glare, were estimated from the actual monitored use. As such, they were included in the optimized model. For the purposes of this analysis, simulations on the model confirmed that the use of internal roller blinds had a positive influence in one season. But this positive effect was counterbalanced by a negative effect in another season. The results of the simulations show that if the internal roller blinds were excluded from the model (i.e., no use of the roller blinds), the energy use in the offices was lower by $2.6 \%$ in the heating season and higher by $2.9 \%$ in the cooling season. The consequence was a total effect of $0.5 \%$, which almost equals a zero-energy effect on the annual simulation output of the whole model. For this example, simulations of the internal air temperatures were also made. Their calculated averages showed noticeable, but very small, deviations in the heating and cooling seasons (Figure 3).

The largest effect on the energy use in the offices, $17.6 \%$ in total, was caused by users' adjustments of the temperature setting with the room-temperature controllers (an adjustment from the general setting of the system). In the heating season, they typically adjusted the temperature higher, while in the cooling season the set temperature was usually lowered. Excluding these adjustments means the general settings of the system apply: $22^{\circ} \mathrm{C}$ in the heating season and $24^{\circ} \mathrm{C}$ in the cooling season. The results of the simulations in this analysis-excluding the temperature adjustments-showed that this resulted in a $13.1 \%$ higher energy use for heating the offices and a $21.2 \%$ higher energy use for cooling them. This phenomenon was reflected primarily in the calculated average internal air temperature in the cooling season, which deviated from the result obtained with the validated result by almost half a degree (Figure 3).

Our goal was also to determine the effect on the results of the combination of all six specific parameters when they were excluded from the model. The simulations showed that the energy effect caused by these specific parameters for the whole year's energy use was $8.2 \%$. If these data were not known and included in the model, the results for energy use would be $8.2 \%$ lower, i.e., $8.2 \%$ less energy would be calculated if all the specific parameters detected by monitoring and analyzed for the purposes of the simulations were excluded from the validated simulation model. As regards the seasons, it was found that the effect on the results was particularly large when cooling. In such a case, $15.9 \%$ less energy would be used just in the cooling season (Figure 3). 


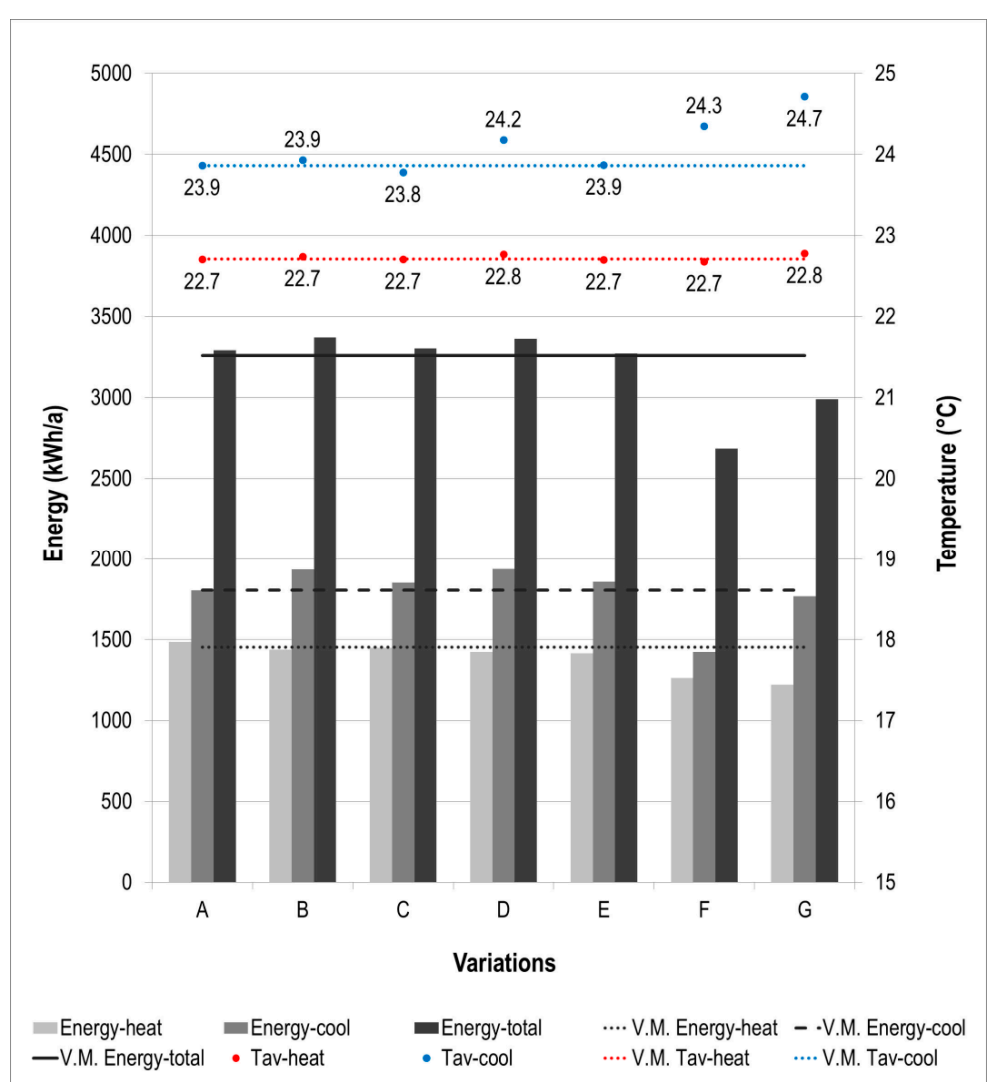

Figure 3. Simulated energy and indoor air temperatures for variations without a specific parameter in comparison with validated model (V. M.): A-without large internal gains; B-without extraction of energy with exhausted air; C-without insufficient energy supply for cooling; D-without window opening by occupants; E-without use of internal roller blinds; F-without temperature adjustments using regulators; and $\mathrm{G}$-without all six specific parameters.

The analysis of the results indicated that some short-term, yet large, inputs have a very small influence on the annual energy level. At the same time, continuous dynamics, such as the use of internal roller blinds, have a very small positive effect in one season and a negative one in another. On the annual level, however, its effect is insignificantly small, as it amounted to only $0.5 \%$. Two inputs in this analysis, i.e., the window opening and the extraction of extra heat with the exhausted air of the mechanical ventilation system due to air-temperature difference, did result in a large effect during one season of $7.0 \%$ and more. Their total annual energy effects were thus $3.2 \%$ and $3.5 \%$, respectively (Figure 3).

The simulations confirmed that the integration of the first five identified parameters had a predominantly moderate but opposite effect on the energy use (decrease or increase) in a particular season. Therefore, they did not have a significant influence on the result of the energy use for a whole year. However, in total they slightly reduced the annual use of energy. Additionally, the analysis proved that, compared with these parameters, the effect of the last, sixth examined parameter, the adjustments of the temperature setting using the room temperature controllers made by users, was the greatest. The use of energy for cooling increased significantly, which is why the annual energy use increased as well.

The analysis revealed that the effect of the five specific parameters contrasts with the effect of the data for the users' temperature adjustments of the temperature setting on the room temperature controllers (they are counteracting). The latter is also the largest; therefore, it dominated in the total annual energy use. It is also clear that the individual effects of specific inputs can be relatively small, 
but their total influence can considerably reduce this largest effect caused by the users when adjusting the room temperature controllers.

At the same time, the simulations also showed one very important fact, which is the relatively large effect on the indoor air temperature in the rooms. In the case when we eliminated all six identified parameters from the model, the average indoor air temperature in the cooling season was noticeably higher; it amounted to $0.85 \mathrm{~K}$ (Figure 3). It is clear that the largest contribution to this deviation was caused by the sixth parameter.

Based on the results of this research we can assume that the interactions of energy effects of such usually unknown parameters could be to a large extent eliminated, in the manner that all the parameters together do not have a significant effect on the result of annual energy use. However, the same does not apply to the indoor air temperatures, for which the results showed crucial and non-negligible deviations.

\subsection{Variation of the Specific Parameters in the Model}

When modeling, it is necessary to have a lot of data directly related to the use of the building. They need to be obtained from the statistics for the type of building concerned, or to be chosen from standard or prescribed values. In the case of our validated model these data were in full accordance to the values obtained from monitoring the offices.

In the continuation of the study, we focused on determining some parameters that would be generalized and suitable for use in similar models. In this sense, a wider group of simulations with variations of an individual parameter was performed in order to define the most appropriate parameter. The analysis included an evaluation of how much the variation of these parameters affects the final results, the energy use and the average indoor air temperature of the offices, compared with the results of the validated model. The basis for all the variations was therefore the validated model. The description of the variations of the validated model used to obtain the generalized parameters is given in Table 2.

Table 2. Results of energy simulations for variations of the parameters of the validated model (S-1 to T-3) and for the validated model with the final combination of selected parameters (G) at annual level.

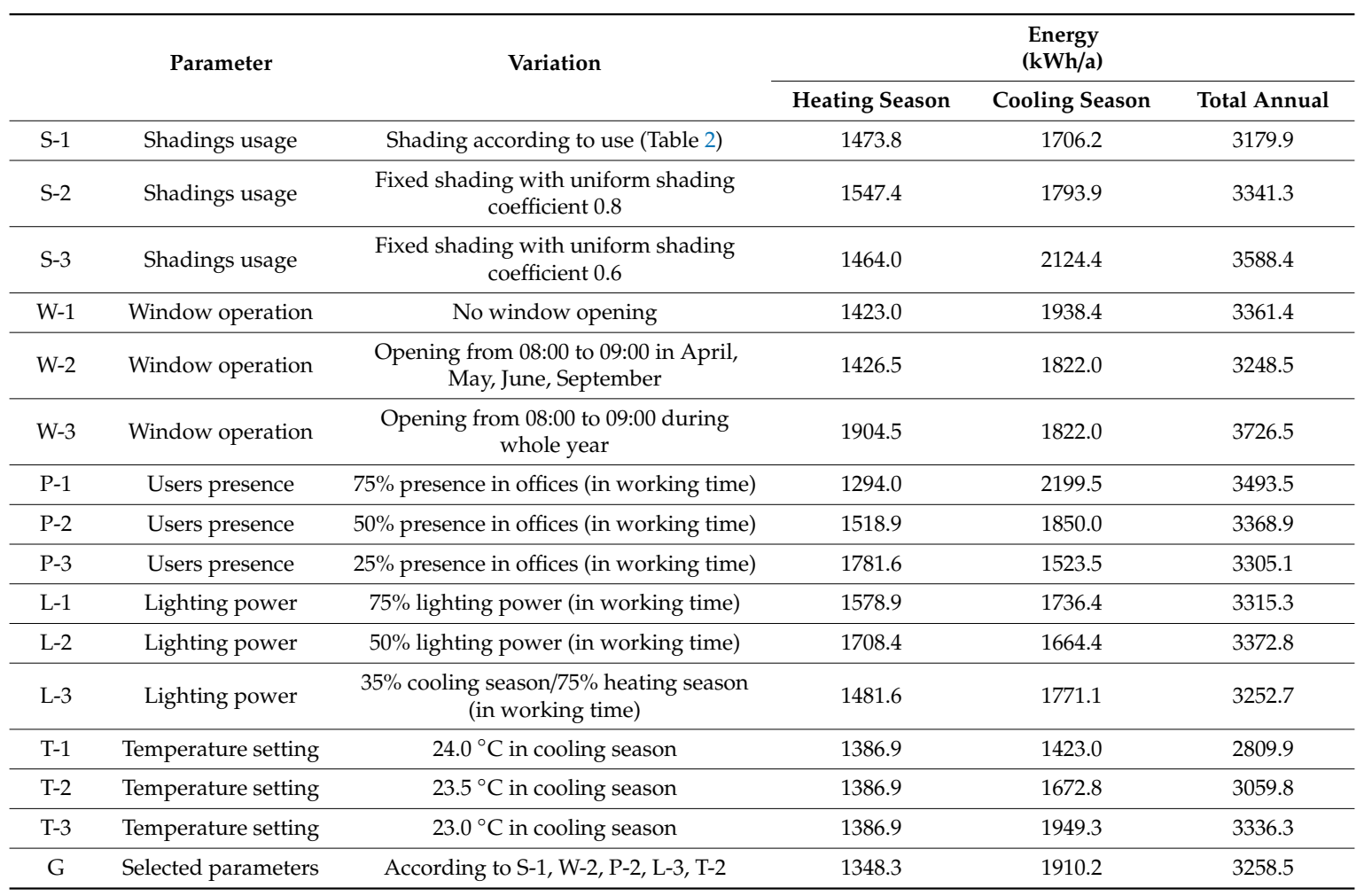


The first simulation set of parameters (S-1 to S-3) refers to the use of external shading devices. For the initial simulation a shading-coefficient assessment was made (Table 3), which was essentially a simplification of the actual use of external shading devices in each individual office and was for this purpose the same for all the windows. For the simulations that followed, two uniform shading coefficients, as a simplification of fixed shading, were used throughout the whole year, i.e., 0.80 and 0.60 , respectively.

Table 3. Estimated common average shading coefficients for all the windows of the model.

\begin{tabular}{cccccccccccc}
\hline Jan & Feb & Mar & Apr & May & Jun & Jul & Aug & Sep & Oct & Nov & Dec \\
\hline 0.40 & 0.45 & 0.60 & 0.65 & 0.70 & 0.70 & 0.70 & 0.70 & 0.70 & 0.65 & 0.60 & 0.40 \\
\hline
\end{tabular}

Among the variations with shading devices, the results of the S-1 variation with an estimated common shading coefficient for all the windows of the model (Table 2) and the variation S-2 with a uniform shading coefficient of 0.8 best matched the results of the validated model. In the first case only $2.4 \%$ less energy for heating and cooling was needed, while in the second case $2.5 \%$ more energy compared to the validated model was needed. The results for the energy use of the S-3 variation were more unfavorable, because the total energy use was $10.1 \%$ higher than the one in the validated model. Similarly favorable results were shown for the average indoor air temperatures: variations S-1 and S-2 were very close to the validated model, while in S-3 the temperatures differed (Figure 3).

The next set of parameters (W-1 to W-3) that we considered in the simulations was related to the strategies of window opening. The parameters included no window opening (W1), scheduled window opening in the morning between 08:00 and 09:00 in the cooling season only (specific months: April, May, June, September) (W-2) and window opening in the morning between 08:00 and 09:00 all year round (W-3) (Table 2). The schedule was based on the actual monitored opening of users, which was most common in the morning, after the user's arrival at work. The comparison of the energy results showed that in this case, the variation $\mathrm{W}-2$ was the one which best matched the results of the validated model. Variation W-2, with manual opening between 08:00 and 09:00 in the morning during the cooling months, provided $1.8 \%$ lower results for energy use in the heating season and $0.9 \%$ higher results in the cooling season, which resulted in $0.3 \%$ lower total energy use compared with the validated model. Also, the average air temperatures in this particular variation were the closest to the temperatures of the validated model (Figure 4).

Two additional important parameters were assessed with the help of simulations: users' presence (and the related operation of devices) and the use of artificial lighting in the offices. The presence of users (P-1 to P-3), which was based on the carefully observed actual use of offices and was primarily determined for the validated model, was changed to rough percentages: $75 \%, 50 \%$ and $25 \%$ presence of the anticipated number of users in the offices during the working time (Table 2). Similarly, the data for the use of artificial lighting was changed from the data that was very accurately defined and used in the validated model, to rough values in percentages in three the variations (L-1 to L-3): $75 \%$ and $50 \%$ of artificial light activation, and a combination 35\% (cooling season) and 75\% (heating season) of artificial light activation (Table 2).

As regards the presence of users (and the associated operation of devices), the closest result for the heating and cooling energy was calculated for variation P-2. The presence of users in P-2 is simplified to $50 \%$ of the anticipated number of users in the working hours. In fact, in the variation P-2, the total energy use deviated slightly more (3.4\%) than in P-3, in which the presence is simplified to $25 \%(1.4 \%)$. However, when observing each season, the matching of results with a validated model are much closer ( $4.6 \%$ higher in the heating season and $2.4 \%$ higher in the cooling season). Additionally, the average air temperatures matched better with the validated model in the case of P-2 than in the case of P-1 (Figure 4).

Since the use of artificial light is related to the season, it was also logical that the result of the simulations for variation L-3 was the best approximation to the result of the validated model. The use 
of energy in the variation L-3, which is a combination of $35 \%$ of artificial light activation in cooling season and $75 \%$ in the heating season, exceeded the one simulated on the validated model in the heating season by $2.0 \%$. In the cooling season, the simulated energy for variation L-3 was $1.9 \%$ lower than the energy simulated with the validated model. Finally, the result of the year-round energy use of the variation L-3 was only $0.2 \%$ lower than the result for the validated model. Similarly, we completed the comparison of the calculated average indoor air temperatures: the results were the most favorable for the variation L-3 (Figure 4).

Important advanced information was obtained with the previous analysis. This showed that the largest effect was caused by the user's adjustments of the temperature setting with the room temperature controllers. Consequently, we tried to find the temperature settings for our model that would be closer to this real use in the offices. It should be mentioned that similar users' behavior is shown by other research studies: temperature settings in rooms are often slightly modified, i.e., raised during the heating mode and reduced in the cooling mode [42]. For this reason, an analysis of the adjustment of setting the temperature for the room temperature controllers was performed in three variations (T-1 to T-3). The analysis included the cooling mode only, since the main effect was detected during this particular period, and the settings were as follows: $24{ }^{\circ} \mathrm{C}, 23.5^{\circ} \mathrm{C}$ and $23{ }^{\circ} \mathrm{C}$ (Table 2). The results for the energy use in the cooling season in versions $\mathrm{T}-2\left(23.5^{\circ} \mathrm{C}\right)$ and $\mathrm{T}-3\left(23.0^{\circ} \mathrm{C}\right)$ were $7.4 \%$ lower or $7.9 \%$ higher, respectively, than the value obtained with the validated model. At the level of annual energy use, the effect in T-2 is slightly higher $(6.1 \%)$ than in T-3 $(2.4 \%)$. However, since in the case of T-2, the use of energy was lower than in the validated model, the latter was chosen as the most appropriate. Additionally, an analysis of the results for the indoor air temperatures showed that the variation T-2 with a setting of $23.5^{\circ} \mathrm{C}$ is closer to the validated model (Figure 4).

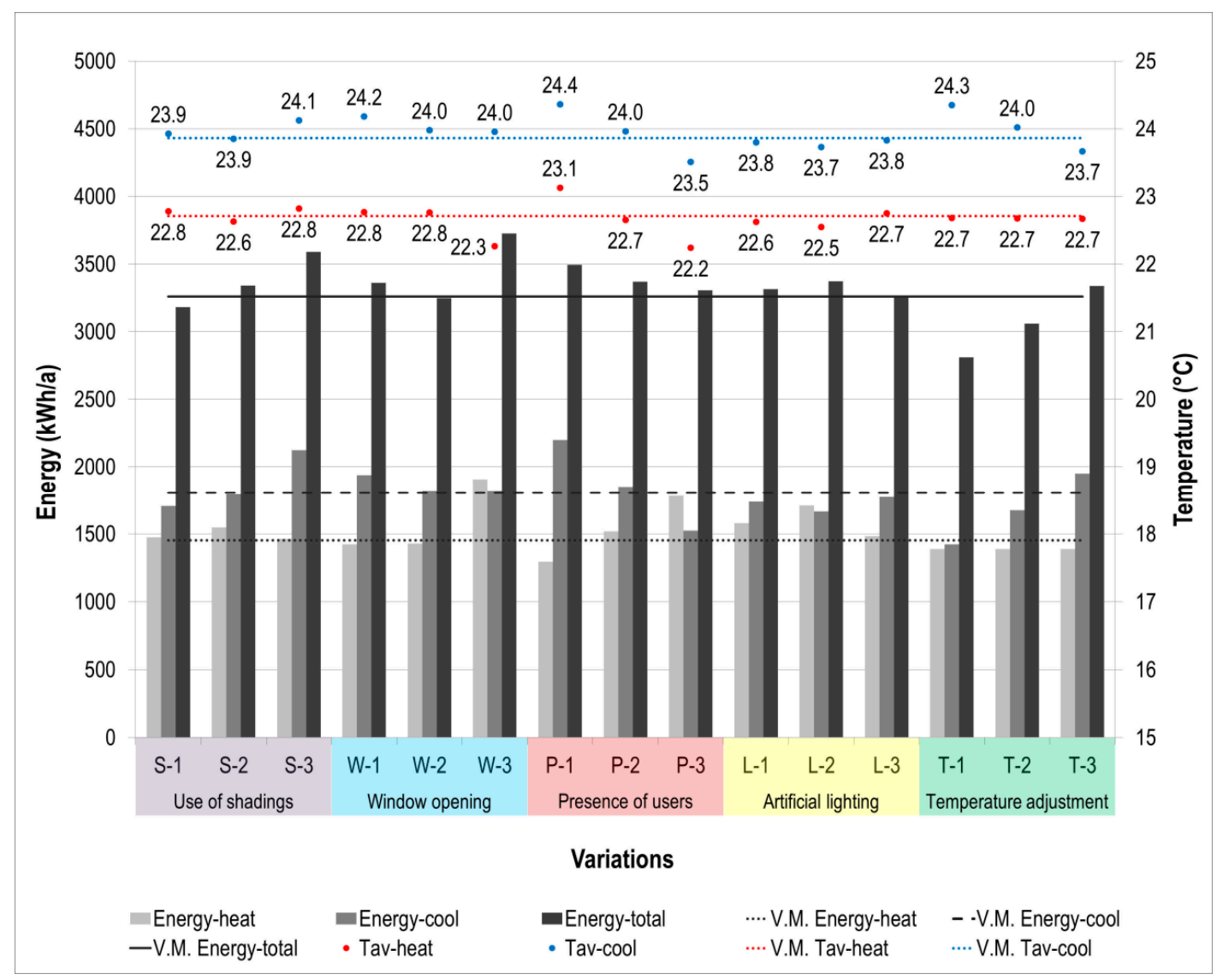

Figure 4. Simulated energy released in offices by ceiling panels and average indoor air temperature for variations of the model according to Table 2 in comparison with the validated model (V.M.). 
Based on the above analyses, a final simulation was performed with the following selected parameters: room temperature regulators set to $23.5^{\circ} \mathrm{C}$ in the cooling season $\left(22{ }^{\circ} \mathrm{C}\right.$ in the heating season; $19^{\circ} \mathrm{C}$ for non-working days), $50 \%$ users' office presence during working hours, $35 \%$ of power of artificial lighting during working hours in the cooling season and $75 \%$ in the heating season, manual opening of windows from 08:00 to 09:00 in specific months of the cooling season (April, May, June, September) and manual shading (with shading coefficients as per Table 3). Specific input data resulting from the previous analysis were excluded from the model.

The deviation of the results for the energy use in the model with generalized parameters compared to the validated model is $7.2 \%$ for heating (7.2\% lower compared with the validated model) and $5.8 \%$ for cooling (5.8\% higher compared with the validated model). This leads to a relatively good overall result on the annual level. Therefore, the simulation result for the total annual energy use on the model with generalized data was practically the same as on a validated model (Figure 4). Based on this, we can conclude that for the cases of determining energy use, a generalization of the parameter is possible.

However, this is not the case with regards to the indoor air temperatures, where moderate seasonal deviations can be seen. On this basis, it is clear that the indoor air temperatures are also an important indicator in the case of the generalization of parameters. The results of both series of simulations (Sections 3.2 and 3.3) lead to the conclusion that the indoor air temperature indicator must also be taken into account in each model of the building.

\section{Discussion}

Our main goal was to determine the effect of particular parameters on the results of energy use and on the indoor air temperature of this simulated system. The focus of the research was on the use of accurate data obtained from measurements and on the possible generalization of the data needed for the simulations.

The simulations on the validated model confirmed that five of the identified parameters (short-term large internal gains in the winter, extraction of energy caused by ventilation, short-term insufficient energy supply for cooling in the summer, window opening, use of internal roller blinds) that were mainly influenced by users did not have a significant effect on the result of energy use on an annual basis. It was also found that the last, sixth observed parameter, the adjustments of temperature setting with the room temperature controllers caused by users, had a relatively large effect on the annual use of energy. However, an additional analysis revealed that the effect of the five specific parameters contrasts with the effect of the users' temperature adjustments to the room temperature controllers. However, the effect of the users' temperature adjustments to the room temperature controllers nonetheless dominated the annual energy use.

It can be concluded that the individual effects of usually unknown specific parameters can be relatively low, but their common effect can considerably reduce the largest effect on energy use, i.e., the users' temperature adjustments to the room temperature controllers. Moreover, if the temperature setting of the room regulators used in such a simulation model would take into account the users' adjustments of the temperature with the room temperature controllers, these lower effects could cancel out the largest one, i.e., the room regulator temperature adjustments, almost completely.

The analysis of the results clearly showed that for the energy simulation the model does not need very accurate data (which are usually unknown). Therefore, parameters such as manual window opening and manual shading can also be predicted or simplified to certain fixed values. However, this is not the case when it comes to evaluating the indoor air temperatures due to the necessity of providing user comfort. That is why it is necessary to include in the models an additional indicator of the modeled indoor environment, i.e., the indoor air temperature. As confirmed by this research, the simulated indoor air temperature showed that a particular solution that meets the targeted requirements for maximum energy efficiency could negatively affect a user's thermal comfort. Therefore, the choice of solutions based exclusively on the favorable results of the energy use of individual variations is by no means recommended. 
This research addressed very detailed parameters within one specific building with a particular system, i.e., offices equipped with radiant ceiling panels. The obtained results, of course, relate to this system. However, most of these parameters generally and in most cases vary independently of the type of heating/cooling system or are virtually unaffected by the heating/cooling system's influence. It could, therefore, be expected that an analysis of such parameters in buildings of the same type would show very similar results. Consequently, our results could probably be applied generally, although the present study was primarily focused on offices equipped with radiant ceiling panels.

\section{Conclusions}

The present study contains a comprehensive analysis of the TRNSYS model, which was optimized by using measurements in selected offices. This optimisation was made by an iterative comparison between the results of dynamic simulations and the data obtained from the monitoring system.

This study confirmed that dynamic simulations, which are important for strategic decisions about the performance of buildings equipped with new technologies or for simulating buildings based on innovative building concepts, should include an evaluation of indoor air temperature in addition to energy use.

Author Contributions: Conceptualization, S.J. and A.L.; methodology, J.H.; validation, S.J.; formal analysis, S.J. and J.H.; writing — original draft preparation, S.J.; writing—review and editing, S.J., M.Z.-S. and A.L.; visualization, S.J.; supervision, M.Z.-S. and A.L.; funding acquisition, S.J. and A.L.

Funding: This research has been carried out within execution of the pilot offices at ZAG through the EU project Cost Effective (Resource- and Cost-Effective Integration of Renewables in Existing High-Rise Buildings, 7FP, 2008-2012) funded by the EU (Grant Agreement No. 212206) and within research work in the P2-0273 Research Program Buildings and materials funded by Slovenian Research Agency.

Conflicts of Interest: The authors declare no conflict of interest. The funders had no role in the design of the study; in the collection, analyses, or interpretation of data; in the writing of the manuscript, or in the decision to publish the results.

\section{References}

1. Jordan, S.; Hafner, J.; Zbašnik-Senegačnik, M.; Legat, A.; Knez, F. Efficient energy use and thermal comfort in the retrofitted pilot offices equipped with radiant ceiling panels. In Proceedings of the 24th Scientific Conference on Energy and the Environment, Opatija, Croatia, 21-24 October 2014.

2. Fonseca-Diaz, N. Modelling of a hydronic ceiling system and its environment as energetic auditing tool. Appl. Energy 2010, 88, 636-649. [CrossRef]

3. Saelens, D.; Parys, W.; Baetens, R. Energy and comfort performance of thermally activated building systems including occupant behavior. Build. Environ. 2011, 46, 835-848. [CrossRef]

4. Lehmann, B.; Guttinger, H.; Dorer, V.; van Velsen, S.; Thiemann, A.; Frank, T. Eawag Forum Chriesbach-Simulation and measurement of energy performance and comfort in a sustainable office building. Energy Build. 2010, 42, 1958-1967. [CrossRef]

5. Buonomano, A.; Palombo, A. Building energy performance analysis by an in-house developed dynamic simulation code: An investigation for different case studies. Appl. Energy 2014, 113, 788-807. [CrossRef]

6. Buratti, C.; Moretti, E.; Belloni, E.; Cotana, F. Unsteady simulations of energy performance and thermal comfort in non-residential buildings. Build. Environ. 2013, 59, 482-491. [CrossRef]

7. Royapoor, M.; Roskilly, T. Building model calibration using energy and environmental data. Energy Build. 2015, 94, 109-120. [CrossRef]

8. Asdrubali, F.; Buratti, C.; Cotana, F.; Baldinelli, G.; Goretti, M.; Moretti, E.; Baldassarri, C.; Belloni, E.; Bianchi, F.; Rotili, A.; et al. Evaluation of Green Buildings Overall Performance through in Situ Monitoring and Simulations. Energies 2013, 6, 5626-6547. [CrossRef]

9. Cornaro, C.; Bosco, F.; Lauria, M.; Puggioni, V.A.; DeSantoli, L. Effectiveness of Automatic and Manual Calibration of an Office Building Energy Model. Appl. Sci. 2019, 9, 1985. [CrossRef]

10. Tam, V.W.Y.; Almeida, L.; Le, K. Energy-Related Occupant Behaviour and Its Implications in Energy Use: A Chronological Review. Sustainability 2018, 10, 2635. [CrossRef] 
11. Solar-Energy-Laboratory. TRNSYS 17, A Transient Simulation Program; University of Wisconsin-Madison: Madison, WI, USA, 1994.

12. Arcuri, N.; Bruno, R.; Bevilacqua, P. Influence of the optical and geometrical properties of indoor environments for the thermal performances of chilled ceilings. Energy Build. 2015, 88, 229-237. [CrossRef]

13. Bonte, M.; Thellier, F.; Lartigue, B. Impact of occupants actions on energy building performance and thermal sensation. Energy Build. 2014, 76, 219-227. [CrossRef]

14. Tian, Z.; Love, J.A. Energy performance optimization of radiant slab cooling using building simulation and field measurements. Energy Build. 2009, 41, 320-330. [CrossRef]

15. Ascione, F.; Bianco, N.; Böttcher, O.; Kaltenbrunner, R.; Vanoli, G.P. Net zero-energy buildings in Germany: Design, model calibration and lessons learned from a case-study in Berlin. Energy Build. 2016, 133, 688-710. [CrossRef]

16. D'Oca, S.; Fabi, V.; Corgnati, S.P.; Andersen, R.K. Effect of thermostat and window opening occupant behavior models on energy use in homes. Build. Simul. 2014, 7, 683-694. [CrossRef]

17. Ryan, E.; Sanquist, T. Validation of building energy modeling tools under idealized and realistic conditions. Energy Build. 2012, 4, 375-382. [CrossRef]

18. Carlander, J.; Trygg, K.; Moshfegh, B. Integration of Measurements and Time Diaries as Complementary Measures to Improve Resolution of BES. Energies 2019, 12, 2072. [CrossRef]

19. Paone, A.; Bacher, J.-P. The Impact of Building Occupant Behavior on Energy Efficiency and Methods to Influence It: A Review of the State of the Art. Energies 2018, 11, 953. [CrossRef]

20. Hong, T.; Yan, D.; D'Oca, S.; Chien-fei, C. Ten Questions Concerning Occupant Behavior in Buildings: The Big Picture. Build. Environ. 2016, 114, 518-530. [CrossRef]

21. Lee, Y.S.; Malkawi, A.M. Simulating multiple occupant behaviors in buildings: An agent-basedmodeling approach. Energy Build. 2014, 69, 407-416. [CrossRef]

22. Fabi, V.; Andersen, R.V.; Corgnati, S.; Olesen, B.W. Occupants' window opening behaviour: A literature review of factors influencing occupant behaviour and models. Build. Environ. 2012, 58, 188-198. [CrossRef]

23. Hong, T.; D'Oca, S.; Turner, W.J.; Taylor-Lange, S.C. An ontology to represent energy-related occupant behavior in buildings. Part I: Introduction to the DNAs framework. Build. Environ. 2015, 92, 764-777. [CrossRef]

24. IEA-EBC Annex 66, Definition and Simulation of Occupant Behaviour in Buildings. Available online: https://www.annex66.org (accessed on 4 October 2019).

25. Yan, D.; O’Brien, W.; Hong, T.; Feng, X.; Gunay, H.B.; Tahmasebi, F.; Mahdavi, A. Occupant behavior modeling for building performance simulation: Current state and future challenges. Energy Build. 2015, 107, 264-278. [CrossRef]

26. Rafsanjani, H.N.; Changbum, R.A.; Mahmoud, A. A Review of Approaches for Sensing, Understanding, and Improving Occupancy-Related Energy-Use Behaviors in Commercial Buildings. Energies 2015, 8, 10996-11029. [CrossRef]

27. Li, H.; Wang, S.; Cheung, H. Sensitivity analysis of design parameters and optimal design for zero/low energy buildings in subtropical regions. Appl. Energy 2018, 228, 1280-1291. [CrossRef]

28. Sun, Y. Sensitivity analysis of macro-parameters in the system design of net zero energy building. Energy Build. 2015, 86, 464-477. [CrossRef]

29. Dussault, J.-M.; Gosselin, L. Office buildings with electrochromic windows: A sensitivity analysis of design parameters on energy performance, and thermal and visual comfort. Energy Build. 2017, 153, 50-62. [CrossRef]

30. Dalong, L.; Wenqin, W.; Jiaping, L. Sensitivity Analysis of Meteorological Parameters on Building Energy Consumption. In Proceedings of the 11th Nordic Symposium on Building Physics, NSB2017, Trondheim, Norway, 11-14 June 2017.

31. Pacheco-Torresa, R.; Heo, Y.; Choudhary, R. Efficient energy modelling of heterogeneous building portfolios. Sustain. Cities Soc. 2016, 27, 49-64. [CrossRef]

32. Tian, W.; Heo, Y.; de Wilde, P.; Li, Z.; Yan, D.; Park, C.S.; Feng, X.; Augenbroe, G. A review of uncertainty analysis in building energy assessment. Renew. Sustain. Energy Rev. 2018, 93, 285-301. [CrossRef]

33. European Commission Cost-Effective Project reports; Final publishable summary report (WP0). Available online: http://www.cost-effective-renewables.eu/includes/images/Publications/Files/ 79abeb4933e416db3960d9592c938ce3.pdf (accessed on 17 July 2015). 
34. Jordan, S.; Kuhn, T.E. Ljubljana's Pilot Demonstration in EU Project Cost Effective. In Proceedings of the World Engineering Forum Sustainable Construction for People, Ljubljana, Slovenia, 17-21 September 2012.

35. Jordan, S.; Hafner, J.; Kuhn, T.E.; Legat, A.; Zbašnik-Senegačnik, M. Evaluation of Various retrofitting Concepts of Building Envelope for Offices Equipped with Large Radiant Ceiling Panels by Dynamic Simulation. Sustainability 2015, 7, 13169-13191. [CrossRef]

36. SIST EN 13829. Thermal Performance of Buildings-Determination of Air Permeability of Buildings-Fan Pressurization Method. Toplotne Značilnosti Stavb_Ugotavljanje Tesnosti Obodnih Konstrukcij-Metoda Tlačne Razlike z Uporabo Ventilatorja; SIST: Ljubljana, Slovenia, 2001.

37. ARSO ARHIV-opazovani in merjeni meteorološki podatki po Sloveniji. Available online: http://www.arso. gov.si (accessed on 7 October 2014).

38. SIST EN ISO 7730. Ergonomija Toplotnega Okolja-Analitično Ugotavljanje in Interpretacija Toplotnega Ugodja z Izračunom PMV in PPD Vrednosti Ter Merili Za Lokalno Toplotno Ugodje; SIST: Ljubljana, Slovenia, 2006.

39. Jordan, S.; Hafner, J.; Kuhn, T.E.; Legat, A.; Zbašnik-Senegačnik, M. Unutarnja okolina renoviranih ureda opremljenih stropnim isijavajućim pločama, Indoor environment in retrofitted offices equipped with radiant ceiling panels. Gradjevinar 2016, 68, 125-134. [CrossRef]

40. EVO International Performance Measurement and Verification Protocol, Concepts and Options for Determining Energy and Water Savings, Volume 1. Available online: http://www.evo-world.org/index.php? lang=en (accessed on 6 November 2014).

41. FEMP M\&V Guidelines: Measurement and Verification for Federal Energy Projects, Version 3.0. Available online: http://mnv.lbl.gov/keyMnVDocs/femp (accessed on 27 August 2014).

42. Barkenbus, J. Indoor thermal comfort: The behavioral component. Sustainability 2013, 5, 1680-1699. [CrossRef]

(C) 2019 by the authors. Licensee MDPI, Basel, Switzerland. This article is an open access article distributed under the terms and conditions of the Creative Commons Attribution (CC BY) license (http://creativecommons.org/licenses/by/4.0/). 